\title{
Effects of Brain Games on Global Cognition among Older Filipinos
}

\author{
Raymund F. Mamayson, Lilia G. Caballes, Kyle Nathaniel B. Asiatico, Rose Angela R. Acosta, \\ Sheantelle Dominique S. Chavez, Lauderdale B. Deocares, Alessandra P. Gayagay, Abigail Ruth K. Lonogan, \\ Vince Rafael B. Nuega, Arianne Joy B. Salvador, Gail Lian B. Santos and June Virlin A. Wooden \\ Saint Louis University, Baguio City, Benguet, Philippines
}

\begin{abstract}
Objective. This study ascertained the effects of brain games on global cognition among older Filipinos.

Methods. A quasi-experimental design was used. The participants were 60 elderly Filipinos, aged 60 to 93 years, residing in Baguio City, and were not engaging in any physical or nutritional interventions to improve cognitive function. None have subclinical cognitive impairments as screened using the Mini-Cognitive Examination. The Addenbrooke's Cognitive Examination-III (ACE-III) tool which correlated significantly with standard neuropsychological tests, and provided a high internal reliability score of 0.88 , was used. Data were analyzed using descriptive and inferential statistics.
\end{abstract}

Results. Pretest mean scores of both active control and experimental groups increased in the posttest. Additionally, both coloring and brain games had extremely significant effects on global cognition ( $p=0.0001)$. Lastly, the unrelated t-test revealed extremely significant difference between the effects of brain games and coloring on global cognition ( $p=0.0001)$.

Conclusions. Based on the results, brain games showed evidence of effectiveness in improving global cognition, and that compared to coloring, it is more effective in improving global cognition among older Filipinos. Variables like motivation and expectancy effects influence the improvement in global cognition among older Filipinos. Lastly, cognitive training using brain games show promise as a non-pharmacologic intervention to address cognitive decline.

Key Words: brain games, global cognition, Filipino older adults

\section{INTRODUCTION}

One of the most significant demographic events in the world today is the rise in the number of older people. In fact, older people are more discernible than ever which may be due to various reasons. For one, the World Health Organization reported declining fertility rates as a major cause. ${ }^{1}$ On the other hand, the United Nations reported remarkable increases in life expectancy secondary to advances in medical technology as another cause. ${ }^{2}$ Together, these have resulted to population aging, which is happening rapidly worldwide.

Globally, older people make up $12.3 \%$ of the population

Paper presented at the $3^{\text {rd }}$ Health, Research, \& Innovation Nursing Students Forum: Today's Students, Tomorrow's Future, July 8-10, 2018, Boromarajonani College of Nursing, Phayao, Thailand; and at the $11^{\text {th }}$ National Nursing Research Conference, February 28March 1, 2019, Supreme Hotel, Baguio City.

Corresponding author: Raymund F. Mamayson, MN, RN Saint Louis University

A. Bonifacio St., Baguio City 2600, Philippines

Email: rfmamayson@slu.edu.ph and in most countries, the population of people aged 60 years and over is growing faster and shows no signs of dwindling. ${ }^{3}$ In the Philippines, the Philippine Statistics Authority 2010 Census for Population and Housing revealed that out of the 92.1 million household populations, $6.8 \%$ were regarded as senior citizens or those aged 60 years and over. ${ }^{4}$ This number increased to $7.48 \%$ or $7,548,769$ out of 
almost 101 million Filipinos in 2015. ${ }^{5}$ These figures show that the aging of the Philippines is not as common as it used to be, and that just like any other country, the Philippines is experiencing population aging.

Together with the increase in the number of older people is an increase in the number of people with agerelated cognitive decline. In particular, although the majority of older Filipinos are in good health and report high levels of well-being, the appearance of age-related changes is inevitable among them. The brains' structure change throughout the lifetime; and normal aging, which is free from Dementia, is linked with structural changes in the brain. ${ }^{6}$ Additionally, Alzheimer's Disease International reported that in the Philippines, 301,000 out of almost 102 million people have Dementia and that by 2030 and 2050 will be around 568,000 and 1.1 million respectively. ${ }^{7}$ These figures show that a proportion of older Filipinos already have problems with thinking, reasoning, and remembering, as well as problems caring for themselves, which lead to poor quality of life (QoL). Hence, there is a need for measures to be implemented to address this emerging health priority.

Opportunely, certain activities to improve cognitive function are available for use by nurses and other healthcare professionals worldwide. Today, major health care efforts to improve cognitive function of older people using a range of interventions exist. For instance, physical exercises are amongst the best-known methods of preventing disability and improving cognition. ${ }^{8,9}$ These exercises are frequently included as part of the information dissemination campaigns of many groups, as well as in the health education activities of nurses. In particular, most exercise guidelines for older people advocate engagement in resistance and aerobic training which provides the most benefit to older individuals. ${ }^{10}$ Simultaneously, extant literature reveals that nutritional modifications or supplementations are also used to prevent cognitive decline which includes Vitamin $\mathrm{B}$ and Vitamin E supplementations, Omega 3 fatty acid, Gingko biloba, and Mediterranean diet. ${ }^{11-15}$

Likewise, BMJ Publishing Group Limited promotes the use of physical and nutritional interventions but added cognitive interventions to address the threats to functional independence arising from the physical and cognitive effects of aging. ${ }^{16}$ Specifically, it was recommended that aside from exercise and diet modifications, older people should engage in leisure activities and cognitive training to further overall function. Leisure activities have been found to have the potential to improve cognitive function among older people such that in one study, it was found that people who frequently participated in cognitive interventions such as playing board games, reading, and playing a musical instrument had a lower risk of developing Dementia. ${ }^{17}$ Moreover, it was found that engagement in functional task exercises demonstrated significant improvements in the domains of general cognitive function, memory, executive function, functional status, and everyday problem-solving ability. ${ }^{18}$
It is with regret though that little attention is given to cognitively-stimulating interventions. Today, most of the activities implemented are physical and nutritional interventions only. For instance, the Department of Health has been continuously promoting exercise and proper nutrition among Filipinos through major programs and projects such as the "Health Lifestyle Program," as well as the "Health Development Program for Older Persons". ${ }^{19,20}$ Additionally, some barangays, senior citizens associations, and older people advocates have programs which promote cognitive functioning among older people such as Zumba sessions in barangays Palma, Trancoville, and Lopez Jaena, ballroom dance contests in barangay Honeymoon, folk dance programs every Tuesdays and Saturdays by the Federation of Baguio Senior Citizens Association, and Tai Chi sessions in Burnham Park by freelance instructors.

In sum, with the increase in the number of older people comes an increase in the number of individuals who experience cognitive decline which negatively impacts QoL. Though government and non-government groups advocating for older people have been responsive to the call of the times, the use of cognitively-stimulating activities, especially newfangled interventions such as brain games and coloring, receive less attention since little evidence is currently available in terms of their effectiveness. Hence, there is a need to determine the effects of such interventions, which served as the primary motivation behind this study.

In particular, this study ascertained the effects of brain games and coloring on global cognition among older Filipinos and determined significant differences in the effects of coloring and brain games on global cognition among older Filipinos.

\section{METHODS}

\section{Study Design}

A quasi experimental, pretest-posttest design was used to determine the effects of brain games and coloring on global cognition among a sample of older Filipinos, and ascertain significant differences in their effects. Although there was random selection and assignment of participants into groups, total control to prevent the influence of extraneous variables from influencing the outcome was not achieved.

\section{Locale}

Due to a reported continuous increase in the number of older people in the Cordillera Administrative Region (CAR), Baguio City was chosen as the locale for this study. In fact, among the 132,893 older people from CAR in 2015,17\% were from Baguio City, making it place as third among the provinces and cities in CAR with the highest number of older people. ${ }^{21}$ Particularly, data gathering sites were Barangays MRR Queen of Peace, Bayan Park Village, South Central Aurora Hill, Trancoville, East Modern Site, Lopez Jaena, Honeymoon, Imelda Village, Camp 7, Palma-Urbano, and Asin Road. 


\section{Sample Selection}

The participants were 60 elderly persons identified through purposive sampling. All participants reported to be Filipinos, aged 60 to 93 years, residing in Baguio City, and were not engaging in any physical or nutritional interventions to improve cognitive function. To minimize the influence of subclinical cognitive impairments, the participants were screened using the Mini-Cognitive examination where none of the participants were excluded on this basis. Additionally, the participants had pretest ACE-III scores ranging from 52 to 80 .

Sample size was determined using the $\mathrm{G}^{*}$ power 3.1.9.2 program $(n=54)$. In anticipation of participant dropouts, the number was increased to 60, such that the two study arms each had 30 participants. All participants provided informed consent.

\section{Instrumentation}

The ACE-III tool was used to gather data and information needed for the study. The ACE-III tool is a brief battery of cognitive tests which evaluates five sub-domains of cognition namely orientation/attention, memory, verbal fluency, language and visuospatial ability. ${ }^{22}$ As a useful tool in determining the level of cognitive functioning, it has been used in earlier research and is available in different languages - Chinese and Spanish. ${ }^{23}$ The original English version was used in this study since based on the researchers' first-hand interaction with older people in Baguio City, they are more fluent and comfortable in using English. Additionally, it correlated significantly with standard neuropsychological tests, and provided a high internal reliability score of 0.88 measured using Cronbach alpha coefficient. ${ }^{23}$

\section{Ethical Approval and Considerations}

This study was conducted according to the guidelines stipulated in the Declaration of Helsinki and all procedures involving human subjects were approved by the Saint Louis University Research Ethics Committee (protocol number SLU-REC 2017-125). Additionally, all activities were done after careful consideration of Republic Act 10173 or the Data Privacy Act of 2012. The anonymity of participants was ensured and all responses were subjected to responsible use and processing of personal data.

\section{Data Gathering Procedure}

This study was a 2 -armed parallel group trial which commenced as soon as ethics approval was received. Initially, communication letters addressed to the different barangay captains were distributed. Upon approval, lists of older people registered in the different barangays were taken and the search for participants was conducted. Prospect participants were asked of their citizenship and age, as well as if they were engaging in physical or nutritional interventions to improve cognitive function.
Moreover, screening for subclinical cognitive impairments was conducted using the Mini-Cognitive Examination. Once eligibility was established, information was provided to the participants which includes data found in the informed consent form. Once informed consent was taken, the participants were subjected to a pretest using the ACE-III tool to determine their baseline scores.

Once pretesting was done, the participants were randomly allocated into the active control and experimental groups. Primarily, the participants were assigned a number from 1 to 60 , where the numbers were written at the upper right corner of their respective ACE-III tools. Thereafter, using the research randomizer free resource program, 30 random numbers were generated after typing the necessary information needed by the program. The ACE-III tools which correspond to the generated numbers were taken and assigned in the active control group, and the remaining tools in the experimental group. A singleblind protocol was implemented where the participants in each group were unaware of the interventions designed for the other group. This step was necessary to avoid staged responses as to how they will perform the interventions.

Participants assigned in the experimental group underwent ten 5-minute brain training sessions using brain games, which are tests and exercises that aim to stimulate several domains of cognitive function to achieve memory boosts, as well as improvement in reasoning skills and executive function among others. ${ }^{24}$ At the start, user accounts were created for each participant. In each session, the participants were required to $\log$ in to their user accounts. After logging in, the participants were given sufficient time to read and understand the instructions shown before playing each game, and were asked to accomplish the brain games within the time limit. Each round lasted for one minute and for every round, the difficulty level increased. At the end of each session, they were asked to logout of their user accounts. On the 10th day, the researchers administered a posttest using the ACE-III tool.

Simultaneously, participants assigned in the active control group underwent ten 30-minute sessions of coloring, known to have calming effects and is suggested by researchers at Johns Hopkins University and the editors of Yoga Journal as a meditation alternative which can potentially enhance the power of cognitive circuits, increase cognitive capacity, increase cerebral perfusion in the prefrontal, parietal and auditory cortex, provide protective effects on the degradation of the gray matter, and enhance areas involved in attention. ${ }^{25-29}$ In each session, the participants were instructed to bring out the coloring materials given to them prior to the first session, and were given a coloring worksheet which was the same for all participants on a daily basis. The participants were instructed to accomplish the worksheet within 30 minutes. On the 10th day, the researchers administered a posttest using the ACE-III tool. 
Immediately after the posttest, the researchers thanked the participants who shared their time. As reciprocity, additional coloring worksheets were provided and the brain game application was installed in the mobile phones of participants upon request. Moreover, the ACE-III tools and other pertinent records were placed in individualized envelopes and kept following guidelines for data retention.

\section{Data Analysis}

Descriptive and inferential statistics were used. Using the ACE-III tool, global cognition composite scores were determined. By adding the scores of each participant, mean pretest and posttest scores were obtained. The paired $t$-test was used to determine the effects of brain games, as well as the effects of coloring on global cognition among older Filipinos.

Conversely, the difference between pretest and posttest scores were taken and mean difference scores were established for both the active control and experimental groups. Significant difference in the mean difference scores of the active control and experimental groups was determined using the unrelated $t$-test.

The researchers performed the computations manually and validated the values using the Microsoft Office Excel 2013 spreadsheet program and its Analysis ToolPak Add-in. The $p$-values were computed using an online probability computing software.

\section{RESULTS AND DISCUSSION}

Interest in examining the benefits of brain training in humans have been increasing in the last few years. In most studies, brain training programs and games were studied on the premise that mental stimulation results to positive brain changes. Based on the researchers understanding after an extensive literature review, this study is the first attempt to investigate the effects of brain games on global cognition among older Filipinos. This experiment on brain games in Baguio City offers some insights as to how the general older adult population can benefit from the use of cognitivelystimulating interventions.

\section{Brain Games and Global Cognition}

Upon using the ACE-III tool to determine the global cognition composite scores, a mean pretest score of 71 was established. This value increased to 86 in the posttest, where a difference of 15 points was derived. A paired $t$-test was conducted to determine significance which resulted to a $t$-statistic of $14.85(p=0.0001)$. The null hypothesis was rejected; hence, there is a significant effect of brain games on global cognition among older Filipinos. Table 1 illustrates the mean pretest and posttest ACE-III scores, the difference between mean scores, as well as the $p$-value.

This finding can be attributed to the effectiveness of brain training in general. To define brain training simply, it
Table 1. Effects of Brain Games on Global Cognition ( $n=30)$

$\begin{array}{cccc}\text { Pretest } & \text { Posttest } & \text { Difference } & \boldsymbol{p} \\ 71 & 86 & 15 & 0.0001^{*}\end{array}$

*Value significant at $p<0.05$

refers to cognitive training that uses intense mental exercises to target and work on the brain's core cognitive skills such as attention, long- and short-term memory, auditory processing, processing speed, logic and reasoning, executive function, and visuospatial skills. ${ }^{24,30}$ Brain training programs and software are carefully made to be able to tap into the brain's plasticity, or its ability to change. In regards to the brain game application used in the study, it was just that. The brain games stimulated the participants' focus, logic, memory, visuospatial, and language skills, resulting in an improvement in global cognition. This is supported by the findings of Palaus et al. where they found that playing games either on computers, consoles, smartphones, or tablets lead to improvements in sustained and selective attention, as well as an enlargement of the hippocampus which is related to visuospatial skills and memory. ${ }^{31}$

Additionally, though the participants only played the games for five minutes in a day, the games were presented to them within a 10-day period, each game having an increasing difficulty level. Thus, the frequency of playing the brain games created a mere-exposure effect which led to the current finding. Using the familiarity principle which states that frequent exposure to a stimulus produces a certain preference for things, the participants were repeatedly exposed to the brain games, thereby, triggering the emergence of a particular preference to engage in it. This particular preference made the participants more inclined to participate in the study until its conclusion, thus facilitating the achievement of its desired effect of improving cognitive function. Moreover, according to the Theory of Self-efficacy by Bandura, when an individual perceives an optimistic self-belief, it can lead to a motivation to perform more effectively and efficiently until the goal is met. ${ }^{32}$ In this study, the improvement of global cognition expected by the participants set their motivation to partake in the study, thus, resulted in a promising outlook and response to an improvement in global cognition.

Lastly, the mental stimulation brought about by the progressive difficulty levels contributed to this finding. The progressive difficulty levels offered some challenge to the participants, making them feel a bit stressed which triggered the release of stress hormones among the participants. Elevated stress hormone levels could directly and indirectly affect cognitive function. In the study, it is possible that the stress hormones indirectly affected global cognition by activating the sympathetic nervous system in charge of the body's fight or flight responses. For instance, adrenaline could have increased the participants' reaction time, norepinephrine could have kept them awake, and cortisol could have increased their blood pressure and sugar; 
all of which contributed to increasing the participants' global cognition composite scores. This is supported by the findings of one study where it was found that mental stress produces sympathoexcitatory responses such as an increase in blood pressure. ${ }^{33}$ On the other hand, stress hormones could have crossed the blood-brain-barrier and directly accessed the brain, which later influenced the participants' cognition and mental health. ${ }^{34}$ In this study, the researchers were unable to determine the levels of stress hormones, and the researchers accept this as a limitation. However, the researchers still believe that the elevated stress hormone levels secondary to the use of brain games contributed to the current findings, to a certain extent.

This finding is consistent with the findings of West et al. where it was found that playing video games was found to promote an increase in hippocampal grey matter which is important for healthy cognition..$^{35}$ On the contrary, this finding goes against that of Foroughi et al. where it was revealed that the improvement in the participants' cognition was due to expectancy effects rather than true training effects, where the positive outlook that the participants had towards the intervention led to a 5- to 10-point increased in the cognitive function tools used. ${ }^{36}$

All told, the use of brain games leads to improvement in global cognition through mechanisms that are poorly understood, but are discussed in extant literature. This finding suggests that nurses and groups advocating for older people can include the use of brain games and other similar cognitive training programs in their plans of care to improve global cognition among older people. Specifically, older people with mild cognitive deficits such as age-associated memory impairments and short-term memory losses would benefit much from this intervention. Ultimately, nurses can use brain games to optimize the cognitive reserves of their older patients, which can aid in the maintenance of psychological wellness - an important element of successful aging.

\section{Coloring and Global Cognition}

Table 2 illustrates the mean pretest and posttest ACE-III scores, the difference between mean scores, as well as the $p$-value. As determined upon usage of the ACEIII tool, the mean pretest score of 66 increased to 74 after exposure to the coloring activity. A difference of merely 8 was established, and although minute, was statistically significant. A $t$-statistic of $7.49(p=0.0001)$ was established which was greater than the critical $t$-value of 2.05 , resulting in failure to accept the null hypothesis. Thus, there is a significant effect of the use of coloring on global cognition among older Filipinos.

Table 2. Effects of Coloring on Global Cognition ( $n=30)$

\begin{tabular}{cccc} 
Pretest & Posttest & Difference & $\boldsymbol{p}$ \\
66 & 74 & 8 & $0.0001^{*}$ \\
\hline
\end{tabular}

*Value significant at $p<0.05$
The minute details of this study show that exposure to a coloring activity leads to an improvement in global cognition. This finding can be attributed to the fact that coloring improves global cognition through mechanisms which enhances attention and memory. First, coloring brings forth relaxation, similar to what is achieved through meditation. Like meditation, coloring facilitates the deactivation of other brain stimulus, thereby enabling the person to focus on the moment and enhances the attention domain of cognition. ${ }^{37}$ Second, coloring enhances memory since the act necessitates that the participants look into the sizes, shapes, and edges of the objects, then associate them with something that has been previously encountered. This process subsequently helps the participants tap into their long-term memory.

On the other hand, the mere 8-point difference between mean scores possibly could have been influenced by certain factors such as the interests of the participants toward the activity, as well as the time of the day when the intervention was administered. Weber has established the relationship between interest and intrinsic motivation, and it could be possible that because the participants were not interested in coloring since they consider it as a basic activity; they were unable to become enthusiastic in performing the intervention. ${ }^{38}$ At the same time, the time of the day might have affected the results since some participants received the intervention during the day when they were active and fully awake, while some received it in the afternoon and rarely in the evening when they might have been tired and sleepy. This was a factor which was difficult to control in this study since the researchers took into consideration the participants' preferred time.

Given this finding, coloring still shows promise in improving global cognition overall. This suggests that nurses could include coloring in their plans of care for patients with mild cognitive deficits such as those with beginning memory impairments. Additionally, nurses and other healthcare workers can promote the use of adult coloring books even to well older people to stimulate mental functioning and prevent the occurrence of diseases such as dementia.

\section{Coloring versus Brain Games}

Using the ACE-III tool, mean pretest and posttest scores were established that became the basis to determine mean difference scores. A mean difference score of 8 was taken from the active control group and 14 in the experimental group. A 6-point difference between mean difference scores exists, and although diminutive, it was statistically significant. The unrelated $t$-test conducted to determine the significant difference between mean difference scores resulted in a $t$-statistic of $4.55(p=0.0001)$, leading to failure to accept the null hypothesis. Therefore, there is a significant difference in the effects of brain games and coloring on global cognition among older Filipinos. Table 3 shows the mean difference scores of the active control and experimental group, as well as the $p$-value. 
Table 3. $\mathrm{t}$-test Result Comparing Equality of Mean Difference Scores $(n=30)$

\begin{tabular}{ccc} 
Coloring Activity & Brain Games & $\boldsymbol{p}$ \\
8 & 14 & $0.0001^{*}$ \\
\hline
\end{tabular}

*Value significant at $p<0.05$

Participants in the active control had a mean difference score of merely 8 , which was 6 points lower than the mean difference score of 14 of participants in the experimental group. These figures denote that greater improvements in cognitive function existed among participants in the experimental group, which could be due to several factors.

First, mental stimulation improves overall cognitive function by stimulating parts of the brain in charge of different cognitive processes like learning, memory, attention, and language among others. Park and Bischof purport that when an individual experiences substantial and sustained demands on cognitive function, plasticity manifests itself more. ${ }^{39}$ Thus, the more cognitive functions involved in brain training programs and activities, the greater the opportunity for neuroplasticity. In this study, the coloring activity conducted merely impinged on the participants' attention, memory, and organizational skills. As compared to brain games which stimulated the participants' focus, logic, memory, visuospatial, and language skills, it is not surprising that the increase in the mean score of participants under the active control group is not large enough.

Second, the current finding may be due to individual variables which affect human learning. Specifically, individual variables that could have affected the findings are motivation, wherein when behavior is motivated, it directs it to a goal; and emotions where a low-intensity tension and anxiety is beneficial to the learning task. ${ }^{40}$ In this study, while it may be true that the participants under both groups were intrinsically motivated to perform the interventions, it appears that participants under the experimental group were more enthusiastic to engage in a new-fangled intervention, making them get higher scores in the posttest. The participants in the active control group appeared less enthusiastic since based on feedback, they considered the activity as something designed for children. Additionally, tension and anxiety subsisted among participants under the experimental group. The intensity of anxiety and tension elicited through the use of brain games was low, thus, benefited the participants during the learning process. Conversely, the active control participants did not feel any form of tension, hence, did not benefit much from the intervention.

Altogether, the current finding supplements and opposes the findings of earlier studies. In particular, it adds on the claims of Nouchi et al. that Brain Age - the brain training game compared to Tetris in their study, improves executive function, working memory, and processing speed in young adults. ${ }^{41} \mathrm{On}$ the other hand, it is incongruent with the findings of Ballesteros et al. where it was found that the experimental group which received training sessions involving non-action video games did not show greater improvements in measures of selective attention and working memory than the active control group which received training involving simulation strategy games. ${ }^{42}$

Nevertheless, the overall findings serve as additional evidence on the effectiveness of cognitively-stimulating interventions which could improve global cognition of older people, both locally and worldwide. This finding has great implications for the healthcare delivery system where healthcare professionals can translate evidence-based findings regarding the use of brain games in their practice to manage cognitive decline which is common among older people. Additionally, the finding implies that further research is necessary to fully establish the effects of brain games on global cognition since currently, there are varied findings. Lastly, nurses and groups advocating for older people can utilize data from this study, or other similar studies, to stimulate policymakers to act on the growing cognitive concerns of older Filipinos.

\section{Limitation of the Study}

Some limitations of this study need to be acknowledged. First, although this study involved a greater number of participants as compared to published studies regarding brain games, generalizations must be done with caution. Second, since Toril et al. found that older people favor shorter training sessions than longer sessions, implementation of a 5-minute daily training session conducted over ten days was implemented in this study. ${ }^{43}$ However, this appears insufficient to determine the effects of brain games on global cognition fully. The researchers recommend a longer period for intervention in future studies which will further explore the effects of brain games. Third, access to the participants became a problem since not all participants were available at any given time. This resulted in variations in the time the interventions were administered which could have influenced the findings. Hence, the researchers recommend to strictly control this factor in future studies. Fourth, this study did not include a passive-control group which could have helped determine the effects of secondary exposure to the ACE-III tool. A passive-control group should be included in future studies to control such effects and influences. Fifth, testing for baseline differences was not performed since the researchers initially planned to conduct a randomized controlled trial. According to the CONSORT 2010 statement, "significance testing of baseline differences in RCTs should not be performed". ${ }^{44}$ Hence, the researchers were unable to determine homogeneity at baseline. Lastly, although it was established that the participants were not engaging in any intervention to improve cognitive function prior to the experiment, the researchers were not able to fully monitor this. For instance, the dietary intake of the participants was something that was hard to control and it could be possible that what they could have been eating 
during the intervention period were foods which stimulate cognitive functioning. Additionally, though the participants were constantly reminded to limit exposure to cognitivelystimulating activities such as watching the television, socialization, and reading literature and newspapers, the researchers were not always available to monitor the activities of the participants. The rate of exposure of the participants to cognitively-stimulating activities might have swayed the findings, thus, should be controlled further in future studies.

\section{CONCLUSIONS AND RECOMMENDATIONS}

Based on the results, brain games show evidence of effectiveness in improving global cognition among older Filipinos. Moreover, more than the use of coloring activities, brain games are more effective in improving global cognition among older Filipinos. Additionally, individual variables such as motivation, as well as expectancy effects influence the improvement in global cognition among older Filipinos. Lastly, cognitive training using brain games or other related software shows promise as a non-pharmacologic intervention to address cognitive decline.

The results of this study provide insight on the effects of brain games on global cognition of older Filipinos, which could be translated into clinical practice. In particular, nurses working in a variety of settings can consider the results of this study and compare it with the findings of previous studies, to come up with a deliberated decision of applying it in the clinical setting. Furthermore, nurses and other professionals working with older people can include the use of brain games in their health education sessions and campaigns to address cognitive decline among older people. Moreover, researchers may consider conducting a study which involves more participants, while simultaneously controlling extraneous variables which could affect the results such as chronologic age and educational background. Lastly, it is recommended that government, non-government organizations, and other groups advocating for older people should develop programs or activities designed to improve global cognition among older people, with emphasis on the use of new-fangled interventions such as brain games.

\section{Statement of Authorship}

All authors have equal involvement during the process of making this article. The article's design, data acquisition, and analysis of its content have been made by consensus among all authors. The authors have approved the final version submitted.

\section{Author Disclosure}

All authors declared no conflicts of interest.

\section{Funding Source \\ None.}

\section{REFERENCES}

1. World Health Organization. Aging and health [Internet]. 2017 [cited 2017 Sep]. Available from http://www.who.int/en/news-room/ fact-sheets/detail/ageing-and-health.

2. United Nations. Ageing [Internet]. 2017 [cited 2017 Sep]. Available from http://www.un.org/en/sections/issues-depth/ageing/index.html.

3. United Nations Populations Fund. Ageing [Internet]. 2015 [cited 2017 Sep]. Available from http://www.unfpa.org/ageing.

4. Philippine Statistics Authority. The Age and Sex Structure of the Philippine Population (Facts from the 2010 Census) [Internet]. 2012 [cited $2017 \mathrm{Sep}$ ]. Available from https://psa.gov.ph/content/age-andsex-structure-philippine-population-facts-2010-census.

5. Philippine Statistics Authority. Philippine Population Surpassed the 100 Million Mark (Results from the 2015 Census of Population) [Internet]. 2017 [cited 2017 Sep]. Available from https://psa.gov.ph/ population-and-housing.

6. Fjell AM, Walhovd KB. Structural brain changes in aging: courses, causes and cognitive consequences. Rev Neurosci. 2010; 21(3):187-221.

7. Alzheimer's Disease International. Dementia in the Asia Pacific Region. London: Alzheimer's Disease International; 2014.

8. Chante C.Mental Benefits of exercise in aging clarified. The Philippine Star [Inyernet]. 2014 March 2 [cited 2017 Sep]. Available from https://www.philstar.com/opinion/2014/03/02/1296136/mentalbenefits-exercise-aging-clarified.

9. Buford TW, Anton SD, Clark DJ, Higgins TJ, Cooke MB. Optimizing the benefits of exercise on physical function in older adults. PM R. 2014; 6(6):528-43.

10. Nelson ME, Rejeski WJ, Blair SN, Duncan PW, Judge JO, King AC, et al. Physical activity and public health in older adults: Recommendation from the American College of Sports Medicine and the American Heart Association. Med Sci Sports Exerc. 2007; 39(8):1435-45.

11. Morris MC, Evans DA, Bienias JL, Tangney CC, Hebert LE, Scherr PA, et al. Dietary folate and Vitamin B12 intake and cognitive decline among community-dwelling older persons. Arch Neurol. 2005; 62(4):641-5.

12. Farina N, Llewellyn D, Isaac M, Tabet N. Vitamin E for Alzheimer's dementia and mild cognitive impairment. Cochrane Database Syst Rev. 2017; 1(1): CD002854.

13. Sydenham E, Dangour AD, Lim W. Omega 3 fatty acid for the prevention of cognitive decline and dementia. Cochrane Database Syst Rev. 2012; (6):CD005379.

14. Jiang L, Su L, Cui H, Ren J, Li C. Ginkgo biloba extract for dementia: A systematic review. Shanghai Arch Psychiatry. 2013; 25(1):10-21.

15. Sofi F, Abbate R, Gensini GF, Casini A. Accruing evidence on benefits of adherence to the Mediterranean diet on health: An updated systematic review and meta-analysis. Am J Clin Nutr. 2010; 92(5):1189-96.

16. BMJ Publishing Group Limited. Optimizing functional status in the elderly [Internet]. 2017 [cited 2017 Sep]. Available from http://www. us.bestpractice.bmj.com/best-practice/monograph/887.html.

17. Wilson RS, Mendes De Leon CF, Barnes LL, Schneider JA, Bienias JL, Evans DA, et al. Participation in cognitively stimulating activities and risk of incident Alzheimer disease. JAMA. 2002; 287(6):742-8.

18. Law L, Barnett F, Yau MK, Gray MA. Effects of functional tasks exercise on older adults with cognitive impairment at risk of Alzheimer's disease: A randomised controlled trial. Age Ageing. 2014; 43(6):813-20.

19. Suerte J. Health lifestyle program to address noncommunicable diseases in PH [Internet]. 2013 [cited 2017 Sep]. Available from http:// www.pchrd.dost.gov.ph/index.php14-r-d-updates/3154-healthlifestyle-program-to-address-noncommunicable-diseases-in-ph.

20. Department of Health Regional Health Office IX. Health and Welfare of Senior Citizens [Internet]. 2017 [cited 2017 Sep]. Available from http://ro9.doh.gov.ph/index.php/health-programs/maternalchild-health/health-and-welfare-of-senior-citizen-program.

21. Philippine Statistics Authority. Senior citizens reached 132 thousand in 2015 [Internet]. 2017 [cited 2017 Dec]. Available from http://rssocar. psa.gov.ph/population/senior-citizens-reached-132-thousand-2015. 
22. Noone P. Addenbrooke's Cognitive Examination-III. Occup Med (Lond). 2015; 65(5):418-20.

23. Hodges J, Larner A. Addenbrooke's Cognitive Examinations: ACE, ACE-R, ACE-III, ACEapp and M-ACE. In: Larner A, editor. Cognitive screening instruments: A practical approach. Switzerland: Springer International Publishing; 2017. pp. 109-37.

24. The SBT Group. Brain Games with HAPPYneuron! [Internet]. 2017 [cited 2017 Sep]. Available from http://www.happy-neuron.com/ our-brain-games.

25. Fitzpatrick K. Why adult coloring books are good for you [Internet]. 2017 [cited 2017 Sep]. Available from http://edition-m.cnn. com/2016/01/06/health/adult-coloring-books-popularity-mentalhealth/index.html.

26. Xiong GL, Doraiswamy PM. Does meditation enhance cognition and brain plasticity? Ann N Y Acad Sci. 2009; 1172:63-9.

27. Newberg AB, Wintering N, Khalsa DS, Roggenkamp H, Waldman MR. Meditation effects on cognitive function and cerebral blood flow in subjects with memory loss: a preliminary study. J Alzheimers Dis. 2010; 20(2):517-26.

28. Pagnoni G, Cekic M. Age effects on gray matter volume and attentional performance in Zen meditation. Neurobiol Aging. 2007; 28(10):1623-7.

29. Lazar SW, Kerr CE, Wasserman RH, Gray JR, Greve DN, Treadway MT, et al. Meditation experience is associated with increased cortical thickness. Neuroreport. 2005; 16(17):1893-7.

30. LearningRx, Inc. Brain Training [Internet]. 2018 [cited 2018 Apr]. Available from https://www.learningrx.com/brain-training/.

31. Palaus M, Marron EM, Viejo-Sobera R, Redolar-Ripoll D. Neural Basis of Video Gaming: A Systematic Review. Front Hum Neurosci. 2017; 11:248.

32. Bandura A. Self-efficacy: Toward a unifying theory of behavioral change. Psychol Rev. 1977; 84(2):191-215.

33. Anderson E, Sinkey C, Mark A. Mental stress increases sympathetic nerve activity during sustained baroreceptor stimulation in humans. Hypertension. 1991; 17(4 Suppl):43-9.
34. Lupien SJ, Maheu F, Tu M, Fiocco A, Schramek TE. The effects of stress and stress hormones on human cognition: Implications for the field of brain and cognition. Brain Cogn. 2007; 65(3):209-37.

35. West GL, Zendel BR, Konishi K, Benady-Chorney J, Bohbot VD, Peretz I, et al. Playing Super Mario 64 increases hippocampal grey matter in older adults. PLoS One. 2017; 12(12):e0187779.

36. Foroughi CK, Monfort SS, Paczynski M, McKnight PE, Greenwood PM. Placebo effects in cognitive training. Proc Natl Acad Sci U S A. 2016; 113(27):7470-4.

37. Dovey D. The Therapeutic Science of Adult Coloring Books: How This Childhood Pastime Helps Adults Relieve Stress [Internet]. 2015 [cited 2018 Apr]. Available from https://www.medicaldaily.com/ therapeutic-science-adult-coloring-books-how-childhood-pastimehelps-adults-356280.

38. Weber K. The relationship of interest to internal and external motivation. Commun Res Rep. 2003; 20:376-83.

39. Park DC, Bischof GN. The aging mind: Neuroplasticity in response to cognitive training. Dialogues Clin Neurosci. 2013; 15(1):109-19.

40. Saint Louis University Department of Psychology. General Psychology. Baguio: Saint Louis University; 1998.

41. Nouchi R, Taki Y, Takeuchi H, Hashizume H, Akitsuki Y, Shigemune $\mathrm{Y}$, et al. Brain training game improves executive functions and processing speed in the elderly: a randomized controlled trial. PLoS One. 2012; 7(1): e29676.

42. Ballesteros S, Mayas J, Prieto A, Ruiz-Marquez E, Toril P, Reales J. Effects of Video Game Training on Measures of Selective Attention and Working Memory in Older Adults: Results from a Randomized Controlled Trial. Front Aging Neurosci. 2017; 9:354.

43. Toril P, Reales J, Mayas J, Ballesteros S. Video game training enhances visuospatial working memory and episodic memory in older adults. Front Hum Neurosci. 2016; 10:206.

44. Moher D, Hopewell S, Schulz KF, Montori V, Gotzsche PC, Devereaux PJ, et al. CONSORT 2010 Explanation and Elaboration: Updated guidelines for reporting parallel group randomized trials. J Clin Epidemiol. 2010; 63(8):e1-37.

The Acta Medica Philippina is now accepting original scientific papers, review articles and case reports for its upcoming issues. Please follow the format for submission as indicated in the "Instructions to Authors" elsewhere in the journal. All papers received shall be properly acknowledged. For inquiries and submission of proposals, please email us at actamedicaphilippina.upm@up.edu.ph 